\title{
MEDIASTINAL LYMPH NODE METASTASIS IN PATIENTS WITH CLINICAL STAGE I PERIPHERAL NON-SMALL-CELL LUNG CANCER
}

Tsuneyo Takizawa, $\mathrm{MD}^{\mathrm{a}}$

Masanori Terashima, $\mathrm{MD}^{\mathrm{a}}$

Teruaki Koike, $\mathrm{MD}^{\mathrm{a}}$

Hideki Akamatsu, MD $^{\text {a }}$

Yuzo Kurita, $\mathrm{MD}^{\mathrm{b}}$

Akira Yokoyama, $\mathrm{MD}^{\mathrm{b}}$
Our aim in this study was to determine the mediastinal areas where lymphadenectomy should be done at the time of surgical resection of clinical stage I lung cancer. Between 1984 and 1994, 575 patients with clinical stage I non-small-cell lung cancer underwent lobectomy and systematic mediastinal lymphadenectomy. Mediastinal lymph nodes were pathologically positive for disease in 79 patients $(14 \%)$, and positive nodes appeared normal intraoperatively in 54 patients $(68 \%)$. Thirty-three percent of those patients with positive $\mathrm{N} 2$ (mediastinal) nodes had negative lobar (N1) nodes. In cancer of the right upper lobe, all N2 cases had the lymph node metastases in the superior mediastinal compartment. In cancer of the right middle lobe, all $\mathrm{N} 2$ cases but one had the metastases in subcarinal or anterior mediastinal nodes. In cancer of the right lower lobe, all $\mathbf{N} 2$ cases but one had the metastases in subcarinal nodes. In cancer of the left upper lobe, all N2 cases had the lymph node metastases in the subaortic compartment. In cancer of the left lower lobe, all $\mathrm{N} 2$ cases but one had the lymph node metastases in the subcarinal area or subaortic compartment. In conclusion, systematic staging of mediastinal lymph nodes is necessary for all patients with resectable clinical stage I lung cancer. The location of the primary tumor determines the mediastinal areas where lymphadenectomy should be done to examine all lymph nodes. (J Thorac Cardiovasc Surg 1997;113:248-52)
$A^{1}$ lthough the negative predictive accuracy for mediastinal lymph node metastasis with the use of computed tomography is high, ${ }^{1,2}$ a few cases of $\mathrm{N} 2$ disease occur among clinical stage I, or clinical N0, tumors. Whereas some authors claim that a radical systematic lymphadenectomy in the mediastinum should be the surgical procedure of choice for all patients with resectable lung cancer, ${ }^{3-5}$ others recommend sampling of lymph nodes in the mediastinum. ${ }^{6,7}$ The extent of lymphadenectomy in the mediastinum is still a matter of controversy. In this study, we investigated the surgeon's intraoperative observation of lymph nodes and the stations of

From the Departments of Thoracic Surgery a and Pulmonary Medicine $^{\mathrm{b}}$ of Niigata Cancer Center Hospital, Niigata, Japan.

Received for publication Nov. 17, 1995; revisions requested Feb. 5, 1996; revisions received July 29, 1996; accepted for publication August 21, 1996.

Address for reprints: Tsuneyo Takizawa, MD, Department of Thoracic Surgery, Niigata Cancer Center Hospital, 2 Kawagishi-cho, 951 Niigata, Japan.

Copyright (C) 1997 by Mosby-Year Book, Inc.

$0022-5223 / 97 \$ 5.00+0 \quad \mathbf{1 2 / 1 / 7 7 4 0 0}$ diseased lymph nodes in patients with clinical stage I peripheral non-small-cell lung cancer (NSCLC).

\section{Patients and methods}

Between January 1984 and December 1994, 575 patients with clinical stage I peripheral NSCLC underwent lobectomy and systematic mediastinal lymphadenectomy at the Department of Thoracic Surgery of Niigata Cancer Center Hospital; these patients formed the study group for this investigation (Table I). Each patient underwent assessment by plain chest roentgenography, bronchoscopy, computed tomographic scan of the thorax and abdomen, and bone scan. The tumor was not visible by bronchoscopy. Bronchoscopic peripheral biopsy or needle aspiration cytologic testing was done to determine the malignancy and histologic type of the cancer. Mediastinal and hilar lymph nodes were measured through a computed tomographic scan of the thorax. Lymph nodes that were $1 \mathrm{~cm}$ or less in short-axis diameter were considered normal. Mediastinoscopy was not used.

Clinical stage I peripheral NSCLC was diagnosed preoperatively in all patients. For the assessment of functional operability, spirography and blood gas analysis were done before operation. Patients in whom the tumor was classified as small-cell lung cancer after operation were excluded. Patients with double primary tumors were also excluded. Patients with minimal pleural invasion were included as patients with $\mathrm{T} 3$ disease. 
Table I. Patient characteristics $(n=575)$

\begin{tabular}{lcc}
\hline & No. & $\%$ \\
\hline Sex & 322 & 56 \\
Male & 253 & 44 \\
Female & & \\
Age (yr) & 65 & \\
Median & $29-83$ & \\
Range & & \\
Histologic type & 432 & 75 \\
Adenocarcinoma & 124 & 22 \\
Squamous cell & 19 & 3 \\
Others & & \\
Cancer location & & \\
Right & 163 & 28 \\
Upper & 53 & 9 \\
Middle & 122 & 21 \\
Lower & & \\
Left & 142 & 25 \\
Upper & 95 & 17 \\
Lower & & \\
T stage & 324 & 56 \\
T1 & 235 & 41 \\
T2 & 16 & 3 \\
T3 & & \\
N stage & 446 & 77 \\
N0 & 50 & 9 \\
N1 & & \\
N2 & & \\
\hline
\end{tabular}

Surgical technique. The surgical approach was by posterolateral thoracotomy in the fourth or fifth intercostal space. The primary lung tumor was resected by lobectomy. The segmental (station 13) and lobar (station 12) lymph nodes were resected with the completion of lobectomy. The interlobar (station 11) lymph nodes and hilar (station 10) nodes were resected before systematic mediastinal lymphadenectomy.

Systematic mediastinal lymphadenectomy was done as described by Naruke, Suemasu, and Ishikawa. ${ }^{4}$ The azygos vein was usually ligated and cut off to open the superior mediastinal compartment. The superior mediastinal (stations 1 to 4) nodes between the trachea and the superior vena cava were dissected from the level of the right subclavian artery to the azygos vein so that the trachea, superior vena cava, and ascending aorta were completely freed from all tissue. The subcarinal (station 7) nodes were removed in all patients. The paraesophageal (station 8 ) and inferior pulmonary (station 9) nodes were routinely included in the dissection in patients with cancer of the lower lobe. The mediastinum anterior to the superior vena cava (station $3 \mathrm{a}$ ) was not always dissected. In cancer of the left side, the subaortic compartment lying between the phrenic nerve, the aortic arch, the left pulmonary artery, and the recurrent nerve to the level of the lower trachea (stations 4 to 6 ) was dissected.

Lobectomy with systematic mediastinal lymphadenectomy was done as completely as possible if the surgeon detected hilar or mediastinal lymph node metastases. The
Table II. Characteristics of patients with N2 disease $(n=79)$

\begin{tabular}{lcc}
\hline & No. & $\%$ \\
\hline Sex & 42 & 53 \\
Male & 37 & 47 \\
Female & & \\
Age (yr) & 65 & \\
Median & $29-78$ & \\
Range & & \\
Histologic type & 63 & 80 \\
Adenocarcinoma & 12 & 15 \\
Squamous cell & 4 & 5 \\
Others & & \\
Cancer location & & \\
Right & 20 & 25 \\
Upper & 6 & 8 \\
Middle & 17 & 22 \\
Lower & & \\
Left & 23 & 29 \\
Upper & 13 & 16 \\
Lower & & \\
T stage & 28 & 36 \\
T1 & 43 & 54 \\
T2 & 8 & 10 \\
T3 & & \\
\hline
\end{tabular}

surgeon reported the intraoperative detection of lymph node metastases immediately after the operation.

Pathologic analysis. All lymph nodes were arranged by the surgeon according to the mapping of the American Thoracic Society. ${ }^{8}$ Each lymph node was examined pathologically and classified as positive or negative for tumor.

\section{Results}

There were 79 patients with $\mathrm{N} 2$ disease (Table II).

Data for 20 cases with mediastinal lymph node metastases from cancer of the right upper lobe are shown in Table III. The surgeon could not detect the lymph node metastasis in 16 cases. Eight cases were without a nodal metastasis in the lobar or hilar area (cases 1, 4 through 8,12,16). All cases had lymph node metastases in the superior mediastinal compartment. Pretracheal (station 3) nodes had the most metastases of all nodes. Subcarinal lymph node metastases were present in one case with bulky nodal metastases (case 19).

Data for six cases with mediastinal lymph node metastases from cancer of the right middle lobe are shown in Table IV. The surgeon could not detect the lymph node metastasis in five cases. Four cases were without nodal metastases in the lobar or hilar area (cases 1, 3, 4, 6). Five cases had lymph node metastases in the subcarinal or anterior mediastinal area (station 3a). Lymph node metastasis in the 
Table III. Mediastinal lymph node metastases from cancer of the right upper lobe

\begin{tabular}{|c|c|c|c|c|c|c|c|c|c|c|c|}
\hline \multirow[b]{2}{*}{ Case } & \multirow[b]{2}{*}{$T$} & \multirow[b]{2}{*}{ Detection* } & \multicolumn{9}{|c|}{ Lymph node station $t$} \\
\hline & & & $3 a$ & 1 & 2 & 3 & 4 & 710 & 11 & 12 & 13 \\
\hline 1 & 2 & $\mathrm{No}$ & & & & & 1 & & & & \\
\hline 2 & 2 & No & & & & & 1 & & & & 2 \\
\hline 3 & 2 & Yes & & & & & 1 & & & 1 & \\
\hline 4 & 2 & No & & & & & 2 & & & & \\
\hline 5 & 3 & No & & & & 1 & & & & & \\
\hline 6 & 3 & No & & & & 1 & & & & & \\
\hline 7 & 1 & Yes & & & & 1 & & & & & \\
\hline 8 & 2 & No & & & & 1 & & & & & \\
\hline 9 & 2 & No & & & & 1 & & & & 1 & \\
\hline 10 & 2 & No & & & & 1 & & & 2 & & \\
\hline 11 & 1 & No & & & & 1 & 1 & & 1 & 1 & 1 \\
\hline 12 & 2 & No & & & & 2 & & & & & \\
\hline 13 & 3 & No & & & & 2 & & & & & 1 \\
\hline 14 & 2 & Yes & & & & 3 & 4 & & & 1 & 1 \\
\hline 15 & 3 & No & & & 1 & & & & 1 & 1 & \\
\hline 16 & 2 & Yes & & & 3 & 1 & & & & & \\
\hline 17 & 2 & No & & 1 & & & & & & 1 & \\
\hline 18 & 2 & No & & 2 & 1 & 1 & & & 1 & 1 & \\
\hline 19 & 2 & No & 1 & 1 & 1 & & 1 & 3 & 2 & 1 & 1 \\
\hline 20 & 3 & No & 1 & 1 & 1 & 3 & 1 & & & 1 & 1 \\
\hline
\end{tabular}

${ }^{*} Y e s$ indicates that the surgeon could detect the lymph node metastasis intraoperatively; no indicates that he or she could not.

$\dagger$ Lymph node stations are numbers according to the American Thoracic Society. ${ }^{8}$ Station $3 \mathrm{a}$ is the mediastinal area anterior to the superior vena cava. A figure in the column of lymph node station is the number of metastatic lymph nodes.

Table IV. Mediastinal lymph node metastases from cancer of the right middle lobe

\begin{tabular}{ccccccccccccc}
\hline & & \multicolumn{8}{c}{ Lymph node station } \\
\cline { 4 - 12 } Case & $T$ & Detection & $3 a$ & 1 & 2 & 3 & 4 & 7 & 10 & 11 & 12 & 13 \\
\hline 1 & 1 & No & & & & & 1 & & & & \\
2 & 1 & No & & & & & 4 & & 1 & & \\
3 & 2 & No & & 1 & & & & & & & \\
4 & 1 & Yes & 1 & & & & & & & & \\
5 & 2 & No & 1 & & & & & 1 & & & \\
6 & 1 & No & 5 & & & & 2 & & & &
\end{tabular}

Data presented as in Table III.

superior mediastinal compartment was present in one case.

Table $V$ shows the findings in 17 cases with mediastinal lymph node metastases from cancer of the right lower lobe. The surgeon could not detect the lymph node metastases in 15 cases. Seven cases were without a nodal metastasis in the lobar or hilar area (cases 1 through 5, 9, and 12). All cases but one had subcarinal lymph node metastases. One case had the metastases only in the inferior pulmonary nodes.
Table V. Mediastinal lymph node metastases from cancer of the right lower lobe

\begin{tabular}{|c|c|c|c|c|c|c|c|c|c|c|c|c|c|}
\hline \multirow[b]{2}{*}{ Case } & \multirow[b]{2}{*}{$T$} & \multirow[b]{2}{*}{ Detection } & \multicolumn{11}{|c|}{ Lymph node station } \\
\hline & & & 1 & 2 & 3 & 4 & 7 & 8 & 9 & 10 & 11 & 12 & 13 \\
\hline 1 & 2 & No & & & & & & & 2 & & & & \\
\hline 2 & 2 & No & & & & & 1 & & & & & & \\
\hline 3 & 2 & No & & & & & 1 & & & & & & \\
\hline 4 & 1 & No & & & & & 1 & & & & & & \\
\hline 5 & 1 & No & & & & & 1 & & & & & & \\
\hline 6 & 1 & No & & & & & 1 & & & & & & 1 \\
\hline 7 & 2 & No & & & & & 1 & & & & & 1 & \\
\hline 8 & 2 & No & & & & & 1 & & & & & 1 & \\
\hline 9 & 2 & No & & & & & 2 & & & & & & \\
\hline 10 & 1 & No & & & & & 2 & & & & 1 & 2 & \\
\hline 11 & 2 & No & & & & & 2 & & 1 & & 3 & 2 & \\
\hline 12 & 3 & Yes & & & 2 & & 2 & 2 & & & & & \\
\hline 13 & 2 & No & 1 & 1 & & & 1 & & & 2 & 1 & & \\
\hline 14 & 2 & No & 2 & & 2 & & 4 & & & & & 5 & 4 \\
\hline 15 & 1 & Yes & 2 & & 2 & & 4 & & & 2 & 2 & 2 & 1 \\
\hline 16 & 1 & No & 2 & & 4 & & 4 & & & & & & 1 \\
\hline 17 & 2 & No & 4 & & 1 & & 2 & & & & 1 & 1 & 1 \\
\hline
\end{tabular}

Data presented as in Table III.

Table VI shows the findings in 23 cases with mediastinal lymph node metastases from cancer of the left upper lobe. The surgeon could not detect the lymph node metastasis in 12 cases. Five cases were without a nodal metastasis in the lobar or hilar area (cases 4, 5, 8, 15, 18). All cases had the lymph node metastases in the subaortic compartment. Subaortic nodes (station 5) had the most metastases of all nodes.

Data for 13 cases with mediastinal lymph node metastases from cancer of the left lower lobe are shown in Table VII. The surgeon could not detect the lymph node metastasis in 6 cases. Two cases were without a nodal metastasis in the lobar or hilar area (cases 4,11 ). Twelve cases had lymph node metastases in the subcarinal area or subaortic compartment. Two cases had the metastasis in the inferior pulmonary lymph node.

\section{Discussion}

There were 79 patients (14\%) with N2 disease among our 575 patients with clinical stage I peripheral NSCLC. The surgeon could not detect the lymph node metastasis in 54 patients $(68 \%)$ with N2 disease. Twenty-six patients with $\mathrm{N} 2$ disease were without a nodal metastasis in the lobar or hilar area, therefore lymph nodes showed a $33 \%$ rate of skip areas involving the mediastinum without involving the lobar area. Although some authors claim that radical systematic lymph node dissection should be 
Table VI. Mediastinal lymph node metastases from cancer of the left upper lobe

\begin{tabular}{|c|c|c|c|c|c|c|c|c|c|c|}
\hline \multirow[b]{2}{*}{ Case } & \multirow[b]{2}{*}{$T$} & \multirow[b]{2}{*}{ Detection } & \multicolumn{8}{|c|}{ Lymph node station } \\
\hline & & & 4 & 5 & 6 & 7 & 10 & 11 & 12 & 13 \\
\hline 1 & 2 & Yes & & & 1 & & & & 1 & \\
\hline 2 & 1 & No & & & 1 & & 1 & & & \\
\hline 3 & 2 & Yes & & & 7 & & 2 & & & \\
\hline 4 & 2 & No & & 1 & & & & & & \\
\hline 5 & 2 & No & & 1 & & & & & & \\
\hline 6 & 2 & Yes & & 1 & & & & & 1 & 1 \\
\hline 7 & 2 & No & & 1 & & & 1 & & 1 & \\
\hline 8 & 1 & No & & 1 & 1 & & & & & \\
\hline 9 & 1 & Yes & & 1 & 1 & & & & 1 & \\
\hline 10 & 2 & Yes & & 2 & & 2 & & & & 1 \\
\hline 11 & 1 & No & & 2 & 1 & & & & & 1 \\
\hline 12 & 1 & Yes & & 2 & 1 & & & & 2 & 1 \\
\hline 13 & 1 & No & & 2 & 1 & & 1 & & & \\
\hline 14 & 2 & Yes & & 2 & 2 & & 2 & & 1 & \\
\hline 15 & 2 & No & 1 & & & & & & & \\
\hline 16 & 1 & No & 1 & & & & & & 1 & 1 \\
\hline 17 & 1 & Yes & 1 & & 1 & & 1 & & 2 & \\
\hline 18 & 2 & No & 1 & & 2 & & & & & \\
\hline 19 & 1 & No & 1 & 1 & & 1 & & & 1 & \\
\hline 20 & 3 & Yes & 1 & 1 & 1 & & & & 2 & \\
\hline 21 & 1 & Yes & 1 & 1 & 2 & & 2 & & & 1 \\
\hline 22 & 2 & No & 1 & 5 & 5 & 1 & 2 & & 1 & \\
\hline 23 & 1 & Yes & 2 & 3 & & 1 & & & 3 & \\
\hline
\end{tabular}

Data presented as in Table III.

done in all patients with resectable primary tumors, ${ }^{3-5}$ the Lung Cancer Study Group recommends the sampling of mediastinal nodes at the time of surgical resection for lung cancer. ${ }^{6}$ Izbiki and colleagues ${ }^{9}$ stated that systematic mediastinal lymphadenectomy is not essential to determine the $\mathrm{N}$ stage, but results in a more detailed staging of the $\mathrm{N} 2$ region, which is of prognostic significance. The extent of lymphadenectomy in the mediastinum is still a matter of controversy.

Our data indicated that the locations of the primary tumors corresponded to the mediastinal areas where lymph nodes were likely to be diseased and the nodal metastasis of a single station often occurred. When the tumor was located in the right upper lobe, the superior mediastinal compartment was the area where lymph nodes had the most metastases and the nodal metastasis of a single station occurred. When the tumor was in the right middle lobe, the subcarina and anterior mediastinum were the areas with like involvement. When the tumor was in the right lower lobe, the subcarina and inferior mediastinum were the respective areas of involvement. When the tumor was in the left upper
Table VII. Mediastinal lymph node metastases from cancer of the left lower lobe

\begin{tabular}{rllllllllllll}
\hline & & \multicolumn{1}{c}{ Lymph node station } \\
\cline { 3 - 12 } Case & $T$ & Detection & 4 & 5 & 6 & 7 & 8 & 9 & 10 & 11 & 12 & 13 \\
\hline 1 & 2 & Yes & & & & & & 1 & & & 1 & 1 \\
2 & 3 & No & & & & 1 & & & & & 1 & \\
3 & 2 & No & & & & 2 & & & & 1 & & \\
4 & 1 & No & & & & 2 & 1 & & & & & \\
5 & 1 & No & & & 1 & & & & 1 & 2 & 1 & \\
6 & 2 & Yes & & & 1 & & & 1 & & & 1 & \\
7 & 1 & Yes & & 1 & & & & & 1 & & & \\
8 & 2 & Yes & & 1 & & 2 & & & 1 & 3 & 3 & \\
9 & 1 & No & & 2 & & 1 & & & 1 & & & \\
10 & 2 & No & 1 & & & & & & & 1 & & 2 \\
11 & 1 & Yes & 1 & & 1 & & & & & & & \\
12 & 2 & Yes & 1 & 1 & & 1 & & & 2 & 1 & & 1 \\
13 & 2 & Yes & 1 & 1 & 2 & 2 & & & 3 & & \\
\hline
\end{tabular}

Data presented as in Table III.

lobe, the corresponding area was the subaortic compartment, and for tumor in the left lower lobe, it was the subcarina and subaortic compartment. We believe that lymphadenectomy should be the choice of surgical procedures in these mediastinal areas.

On the other hand, our data indicated that the locations of the primary tumors corresponded to the mediastinal areas where lymph nodes were rarely positive, but when positive, always involved multiple nodes. When the tumor was located in the right or left upper lobe, the subcarina was the area where lymph nodes were rarely positive but when positive, always involved nodal diseases in multiple stations. When the tumor was in the right lower lobe, the superior mediastinal compartment was similarly involved as described for the upper lobes. We recommend sampling of lymph nodes in these mediastinal areas unless nodal disease is suspected in the mediastinum. The Lung Cancer Study Group reported a poor survival for patients with nodal disease in the subcarinal and any other mediastinal area. ${ }^{6}$ When a nodal disease in the subcarinal area is suspected in a patient with cancer of the right or left upper lobe, the surgical treatment must be considered carefully because a positive subcarinal node suggests multiple nodal involvement in the mediastinum. When lymph node metastasis in the superior mediastinal compartment is proved in a patient with cancer of the right lower lobe, surgical treatment may be useless because a positive node in the superior mediastinal compartment suggests multiple nodal disease in the mediastinum. 
In conclusion, systematic staging of mediastinal lymph nodes is necessary for all patients with resectable clinical stage I lung cancer. The location of the primary tumor determines the mediastinal areas where lymphadenectomy should be done to examine all lymph nodes.

\section{REFERENCES}

1. Lewis JW Jr, Pealberg JL, Beute GH, Alpern M, Kvale PA, Magilligan DJ Jr. Can computed tomography of the chest stage lung cancer: yes and no. Ann Thorac Surg 1990;49:591-6.

2. Izbicki JR, Thetter O, Karg O, et al. Accuracy of computed tomographic scan and surgical assessment for staging of bronchial carcinoma. J Thorac Cardiovasc Surg 1992;104:413-20.

3. Martini N, Flehinger BJ, Zaman MB, Beattie EJ Jr. Results of resection in non-oat cell carcinoma of the lung with mediastinal lymph node metastases. Ann Surg 1983;198:386-97.

4. Naruke T, Suemasu K, Ishikawa S. Surgical treatment for lung cancer with metastasis to mediastinal lymph nodes. J Thorac Cardiovasc Surg 1976;71:279-85.

5. Watanabe Y, Shimizu J, Tsubota M, Iwa T. Mediastinal spread of metastatic lymph nodes in bronchogenic carcinoma. Chest 1990;97:1059-65.

6. Thomas PA, Piantadosi S, Mountain CF, et al. Should subcarinal lymph nodes be routinely examined in patients with non-small-cell lung cancer? J Thorac Cardiovasc Surg 1988; 95:883-7.

7. Funatsu T, Matsubara Y, Ikeda S, Hatakenaka R, Hanawa T, Ishida $\mathrm{H}$. Preoperative mediastinoscopic assessment of $\mathrm{N}$ factors and the need for mediastinal lymph node dissection in T1 lung cancer. J Thorac Cardiovasc Surg 1994;108:321-8.

8. Tisi GM, Friedman PH, Peters RM, et al. American Thoracic Society: clinical staging of primary lung cancer. Am Rev Respir Dis 1983;127:659-64.

9. Izbicki JR, Passlick B, Karg O, et al. Impact of radical systematic mediastinal lymphadenectomy on tumor staging in lung cancer. Ann Thorac Surg 1995;59:209-14.

\section{Bound volumes available to subscribers}

Bound volumes of The Journal of Thoracic and Cardiovascular Surgery are available to subscribers (only) for the 1997 issues from the Publisher, at a cost of $\$ 110.50$ for domestic, $\$ 139.64$ for Canadian, and $\$ 130.50$ for international subscribers for Vol. 113 (January-June) and Vol. 114 (July-December). Shipping charges are included. Each bound volume contains a subject and author index and all advertising is removed. Copies are shipped within 60 days after publication of the last issue of the volume. The binding is durable buckram with the Journal name, volume number, and year stamped in gold on the spine. Payment must accompany all orders. Contact Mosby-Year Book, Inc., Subscription Services, 11830 Westline Industrial Drive, St. Louis, Missouri 63146-3318, USA; phone $800-453-4351$ or $314-453-4351$.

Subscriptions must be in force to qualify. Bound volumes are not available in place of a regular Journal subscription. 